\title{
Habitat use and maternal care of Phloea subquadrata (Hemiptera: Phloeidae) in the Brasilian Atlantic forest (Espirito Santo)
}

\author{
ERIC GUILBERT \\ Muséum National d'Histoire Naturelle, ESA 8043 CNRS, Laboratoire d'Entomologie, 45, rue Buffon, 75005 Paris, France; \\ e-mail: guilbert@mnhn.fr
}

Key words. Maternal care, behavior, Hemiptera, Phloeidae, Atlantic forest, semi-deciduous forest, Brasil

\begin{abstract}
Phloea subquadrata (Hemiptera, Phloeidae) was observed in two natural reserves of the Brazilian Atlantic forest near Linhares (Espirito Santo). This species exhibits maternal care which is also known for the two other species of the family: Phloea corticata and Phloeophana longirostris. They protect the eggs and also the larvae from predation by covering them with their body. Such behavior is known for other species of Hemiptera, but with some variations. The evolutionary significance of phloeid behaviour is discussed with reference to the behaviour of Hemiptera in general.
\end{abstract}

\section{INTRODUCTION}

Phloeidae is a small family of Pentatomoidea (Hemiptera), represented by only three species: Phloeophana longirostris (Spinola, 1837), Phloea corticata (Drury, 1773) and Phloea subquadrata Spinola, 1837. All three live in Brazil. Phloea corticata is also known from French Guyana. These curious sap-suckers live on tree trunks. Phloea subquadrata feeds on Eugenia cauliflora de Berg (Myrtaceae), Sucurinega guaraiuva Kuhlmann (Euphorbiaceae), and other species of Myrtaceae. ("araçá") (Lent \& Jurberg, 1965). The shape and colour of Phloeidae are such that they are homochromous with the tree trunk or mimetic, resembling patches of lichens. Phloea corticata and Phloeophana longirostris lay eggs on the bark and shield them with their body, probably to protect them against predation (Magalhães, 1909; Tallamy \& Schaefer, 1997). After hatching the larvae stay under the mother, fixed to her abdomen (Magalhães, 1909; Hussey, 1934; Leston, 1953; Lent \& Jurberg, 1966). Nothing is known about the biology of Phloea subquadrata.

Subsocial behaviour and parental care are known for many heteropteran families, mainly with the Pentatomoidea, to which the Phloeidae belongs. Phloeidae are one of the few groups of Hemiptera that carry their brood fixed under the abdomen. One explanatory hypothesis is that maternal care evolved in this group to facilitate feeding as well as protection (Tallamy \& Schaefer, 1997). We described here observations on the natural history of Phloea subquadrata on a new host plant, Terminalia $c f$. kulhmannii Alwan \& Stace (Combretaceae). This tree is known as "pau pelada" and "araçá" in Espirito Santo, or "araçá d'água" in Bahia. The behaviour and, particularly, the maternal care of $P$. subquadrata is discussed in an evolutionary context.

\section{METHOD}

Observations were made at two sites within natural forest reserves located in northern Espirito Santo state in south eastern
Brazil $\left(19^{\circ} 03^{\prime}-19^{\circ} 12^{\prime} \mathrm{S} ; 39^{\circ} 52^{\prime}-40^{\circ} 12^{\prime} \mathrm{W}\right)$. Each reserve represents a forest fragment from larger than 20,000 ha. One of the sites was located in the Linhares forest reserve, belonging to the Companhia do Vale do Rio Doce (CVRD), and the other in Sooretama biological reserve (IBAMA). Both are tropical semideciduous forests on Tertiary tablelands ("Mata de tabuleiros") (Rizzini, 1963). The sites were visited several times during three surveys in October 1999, November 2000 and October 2001, totalling 25 hours of observation in each site. Trunks of Terminalia cf. kuhlmannii, one of the host-plants of Phloeidae, were examined at all the sites. When Phloeidae were found, the number of individuals and their position on the trunk were recorded. Females were examined to check if they were brooding. Other observations of breeding were made at Itabuna (Bahia state) during October 2001, also in semi-deciduous Atlantic forest.

\section{RESULTS}

Phloea corticata was found in the same localities and also on the same host-plant as P. subquadrata. Phloeophana longirostris was absent while no data were recorded for $P$. corticata.

Phloea subquadrata in this study occured on "pau pelada" (Terminalia cf. kuhlmannii Alwan \& Stace, Combretaceae). No phloeid was found on any other tree species. This species was also recorded for the first time from Bahia state (Itabuna), on T. cf. kuhlmannii.

The total number of $P$. subquadrata observed was 1408 individuals. All nymphs occurred within aggregates although some solitary adults were encountered. All of the individuals sharing the same tree were considered to belong to the same "colony", even if divided into several aggregates, because they are potentially in contact with each other. Conversely, each colony is quite isolated, one tree to another, because phloeids do not fly (Magalhães 1909).

Fourteen females were observed at Itabuna protecting eggs ( 20 to 27 eggs) laid low down on a trunk. The eggs are whitish, grouped in a rounded clutch and entirely covered by the female body. The females cover the eggs until they hatch, but the time between laying and hatching was 

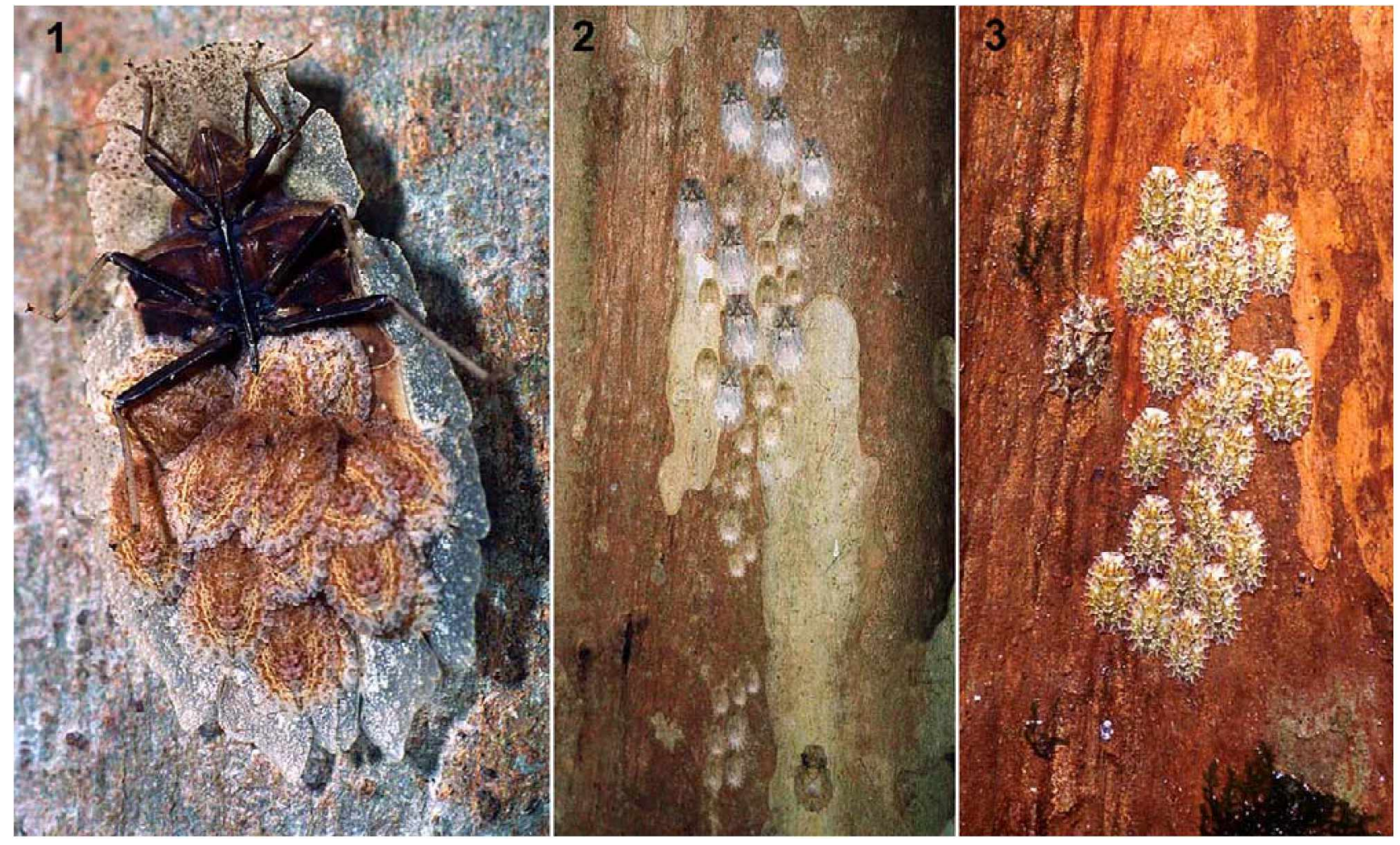

Fig. 1. Female of Phloea subquadrata with her brood (20 first nymphal instars) clinging to her abdomen. Fig. 2. Aggregates of Phloea subquadrata on a T. cf. kulhmannii presumably from the same population.

Fig. 3. Brood of Phloea corticata with the mother forming a compact aggregation on a $T$. cf. kulhmannii.

not observed. When eggs hatch, the young larvae stay under the mother fixed to the abdomen. Three females were observed at Linhares and Sooretama with 20,21 and 27 larvae, respectively, fixed under the mother, with the larval dorsa against the bark (Fig. 1). They leave the mother after the first moult ( 8 days after hatching) but not all at the same time. After leaving the mother, the larvae stay aggregated close to her. Several broods involving several adults can merge, to form large aggregations. Some aggregations were spaced on the trunk over several meters (Fig. 2). The colonies moved on the same trunk and were not at the same place two to seven days later. Two remained in the same place for 15 days.

Many specimens ejected jets of liquid regularly every 5 to 10 minutes, but most were observed for long periods without exhibiting this behaviour.

\section{DISCUSSION}

My observations show that females of $P$. subquadrata lay eggs on bark, care for the eggs by covering them, and also for larvae by carrying them under the abdomen. The larvae stay under the mother throughout the first larval stage, and then leave the abdomen of the mother, and form aggregations close to her. Aggregations move as groups up the host-tree during development but become "looser" over time. It is doubtful that the disappearance of entire colonies on the trunk from one day to another can be explained by predator pressure, and no specimens were found in the litter around the trees.
Observations of parental care have also been made for Phloeophana longirostris by Magalhães (1909) and Brien (1930), subsequently criticized by Leston (1953). The number of eggs laid by $P$. longirostris is smaller ( 8 to 12 eggs) than I observed for $P$. subquadata, and the larvae stay under the mother until they reach the third larval stage. Magalhães (1909) mentioned that some last larval stages were still under the mother. I doubt that larvae of $P$. longirostris stay until the last larval stage under the abdomen of the mother because of their size and number. Furthermore, larvae cannot feed from bark while attached to their mother's abdomen.

Similar observations were described for Phloea corticata by Magalhães (1909) quoting Schiödte's work (1845 in Magalhães, 1909). Schiödte mentioned that the larvae of $P$. corticata under the mother were first instars. I also found a brood of $P$. corticata of 21 larvae with the mother (Fig. 3). Accordingly, the three known species of Phloeidae all appear to have the same habits of maternal care.

Brien (1930) suggests that phloeid larvae feed from their mother because their stylets are too short to penetrate the bark of the host-plant. However, no observation was made on the way they feed. Bequaert (1935) and Margalhães (1909) suggested that larvae feed on some of the sap of the tree oozing out along the mother's proboscis. Magalhăes stated also that the mother ejects a jet of liquid as a defence reaction, and Poisson (1951 in Leston, 1953) argued that this jet could be used to feed the larvae. However, the larvae cannot use the ejected 
liquid because it is directed away from them. Furthermore, during my observations, the ejecting behaviour was unrelated to disturbance. They did not eject when collected. These observations suggest that the phenomenon is not a defence reaction, but could have an excretory function as suggested by Leston (1953). It is also unlikely that larvae use their rostrum to suck liquid oozing out along the maternal proboscis. Direct feeding by the larvae from their mother's gut through the intersegmental membranes is also not verified. Twenty larvae piercing their mother's abdomen and sucking her gut's substance would be detrimental for the mother. Second, there are no scars on the mother's intersegmental membranes.

Parental care is known from heteropteran species in different families. Many protect the eggs until hatching, some also protect the larvae, but few carry their brood, and even fewer carry them under their abdomen as do the Phloeidae. Tallamy \& Schaefer (1997) discussed the evolutionary value of maternal care in the Hemiptera. They argued that there are no heteropteran taxa that lay large, exposed clutches without providing care; but the converse is also true; all subsocial species lay large clutches that are either exposed on the substrate or, less often, in ground cavities. Quoting Bequaert (1935), they also argued that the Phloeidae are the single exception because females hide eggs in bark crevices and cover them with their bodies until eclosion. The females of $P$. subquadrata observed on $T$. cf. kulhmannii at Itabuna were covering eggs that had been laid on the bark but not in crevices. In addition, the bark of $T$. cf. kulhmannii where $P$. corticata was also found, did not have crevices. Egg protection should be more efficient in the case of Phloeidae because of their homochromous body pattern. The Phloeidae are not an exception. They do guard eggs, exposed or not. They also guard larvae as do some other Pentatomoidea (Gogala et al, 1998; Sinclair, 2000). Margalhães observed that the mother came back to guard her brood when moved. I observed that the larvae (second or third stages) regrouped under the adults when caught and released. Such reactions indicate the protective role of the mother. The question of larval feeding remains unresolved. If larvae do feed from the mother, protection of larvae could be a consequence of the feeding habit but, conversely, feeding facilitation could be a consequence of an advanced form of protection.
ACKNOWLEDGEMENTS. I would like to thank R. Moraes de Jesus, head of the Reserve of Linhares (CVRD), who gave me access to the reserve, C. Rizzini and F. Vieira Agarez from the Department of Botany of the Federal University of Rio de Janeiro, for providing botanical and physical information on the study sites, P. Grandcolas, C. Villemant, and R. Pellens for their field assistance, and D.W. Tallamy for helpful comments on the manuscript. The observations at Itabuna were made by $\mathrm{C}$. Villemant. The photographs were taken by P. Grandcolas. This study was carried out in the framework of a CNRS/CNPq program (Proc. 910076/99-5) on Insects Diversity and Forest Fragmentation in Brazilian Atlantic forest (Espirito Santo), managed by $\mathbf{J}$. Najt (ESA 8043 CNRS, France) and I. Garay (Dept. of Botany UFRJ, Brazil).

\section{REFERENCES}

Bequaert J. 1935: Presocial behavior among the Hemiptera. Bul. Brooklyn Entomol. Soc. 30: 177-191.

Brien P. 1930: Notes sur Phloea paradoxa Burm., Mission Biologique Belge au Brésil (1922-1923), Vol 2, Brussels, pp. 207-212.

Gogala M., Yong H.-S. \& BRÜhl C. 1998: Maternal care in Pygoplatys bugs (Heteroptera: Tessaratomidae). Eur. J. Entomol. 95: 311-315.

Hussey R.F. 1934: Observations on Pachycoris torridus (Scop.), with remarks on parental care in other hemiptera. Bul. Brooklyn Entomol. Soc. 29: 133-145.

LeNT H. \& JuRBerg J. 1965: Contribuição ao conhecimento dos Phloeidae Dallas, 1851, com um estudi sôbre genitàlia (Hemiptera: Pentatomoidea). Rev. Bras. Biol. 25: 123-144.

Lent H. \& Jurberg J. 1966: Os estádios larvares de "Phloeophana longirostris" (Spinola, 1837) (Hemiptera: Pentatomoidea). Rev. Bras. Biol. 26: 1-4.

Leston D. 1953. "Phloeidae" Dallas: systematics and morphology, with remarks on the phylogeny of "Pentatomoidea" Leach and upon the position of "Serbana" Distant (Hemiptera). Rev. Bras. Biol. 13: 121-140.

Magalhães DE P.S. 1909: Contribution à l'histoire naturelle des Phlées. Mém. Soc. Zool. Fr. 22: 234-260.

RIzzinI C.T. 1963: Nota prévia sobre a divisão fitogeográfica (florística-sociológica) do Brasil. Rev. Bras. Geogr. 25: 3-64.

SinClatr D.P. 2000. A generic revision of the Oncomerinae (Heteroptera: Pentatomoidea: Tessaratomidae). Mem. Queens. Mus. 46: 307-329.

Tallamy D.W. \& Schaefer C. 1997: Maternal care in the Hemiptera: ancestry, alternatives, and current adaptative value. In: Choe J.C. \& Crespi B.J. (eds): The Evolution of Social Behavior on Insects and Arachnids, CUP, Cambridge, pp. 94-115.

Received December 14, 2001; revised May 20, 2002; accepted August 15, 2002 